Article

\title{
Assessing the Difference of Emotional Intelligence among Visually Impaired, Blind Cricketers, and Non-Cricketers
}

\author{
Sarmad Hussain ${ }^{1} \mathbb{D}$, Asif Ali $^{2}$, Young Gin Choi ${ }^{3}$ and Jinsoo Hwang ${ }^{4, * \mathbb{D}}$ \\ 1 Special Education Department, Multan 66000, Pakistan; sarmad.aceplayer@gmail.com \\ 2 Department of Physical Education \& Sports Sciences, Govt. College University, Lahore 54000, Pakistan; \\ goraya128@hotmail.com \\ 3 Recreation, Park and Tourism/Hospitality Management, Western Illinois University, Macomb, MI 61455, USA; \\ yg-choi@wiu.edu \\ 4 The College of Hospitality and Tourism Management, Sejong University, 98 Gunja-Dong, Gwanjin-Gu, \\ Seoul 143-747, Korea \\ * Correspondence: jhwang@sejong.ac.kr
}

Citation: Hussain, S.; Ali, A.;

Choi, Y.G.; Hwang, J. Assessing the Difference of Emotional Intelligence among Visually Impaired, Blind Cricketers, and Non-Cricketers. Sustainability 2021, 13, 2955. https:// doi.org/10.3390/su13052955

Academic Editor: Seong Ok Lyu

Received: 29 January 2021

Accepted: 3 March 2021

Published: 9 March 2021

Publisher's Note: MDPI stays neutral with regard to jurisdictional claims in published maps and institutional affiliations.

Copyright: (c) 2021 by the authors. Licensee MDPI, Basel, Switzerland. This article is an open access article distributed under the terms and conditions of the Creative Commons Attribution (CC BY) license (https:/ / creativecommons.org/licenses/by/ $4.0 /)$.

\begin{abstract}
Background: Emotional intelligence plays a critical role in one's socialization and psychological adjustment. The current study is an attempt to obtain a comparative analysis of the emotional intelligence among the cricketers that are blind or suffer from visual impairment. The major objective of the study is to measure the emotional intelligence of visually impaired athletes along with the influence of their physical activities and demographic variables. (2) Methods: The employed survey method, with a descriptive research design, was based on a selective purpose sample of 220, which included a mean age of 28.38 years and an age range from 18 to 40 years, visually impaired cricketers, and non-cricketers from Punjab. The selective individuals completely provided their demographic information by filling out two forms, which included the short-form trait emotional intelligence questionnaire (TEIQue-SF) and the international physical activity questionnaire (IPAQSF). (3) Results: There is a significant relationship with emotional intelligence among the cricketers that are blind or suffer from visual impairment. Furthermore, the demographic variables had a significant impact on emotional intelligence (EI). Based on these findings, this study suggests administering a longitudinal study of visually impaired athletes in future research. In addition, different statistical populations of visually impaired athletes can be studied in order to compare their emotional intelligence with other psychological variables.
\end{abstract}

Keywords: trait emotional intelligence; visually impaired cricketers; physical activity

\section{Introduction}

Emotions play an important role in determining human behavior. According to researchers [1], the ways individuals think, communicate, and take action largely hinge on certain skills that they possess to handle their emotions. In another definition, emotional intelligence (EI) is the skill that people possess to examine other people's emotions and their own emotions, to differentiate between them, and to utilize them to conduct one's actions and thinking [2]. The suggestion of EI was initiated [2], and it was later augmented in a successful book called Emotional Intelligence that was written by Goleman [3]. EI enables peoples to recognize, review, and control their own emotions and others' emotions in the community [3]. Goleman identified that cognitive skill traits account for twenty percent of achievements with work, academics, and personal life, whereas eighty percent is due to emotional intelligence [4]. The consideration of EI's concept rapidly increased afterward in most studies. EI is directly related to personal characteristics. The characteristics include well-being, an individual's performance, and their associations with others [5]. Emotions and emotional intelligence are both renowned as being the considerable factors in the area of sports psychology; they help to enhance athletes' performance in sports [6,7]. To 
maximize strength in a game, the individual must have skills to understand as well as have a grip on their emotions. Afterward, it was discovered that the importance of EI has been rising in the study of physical activities [8]. Particularly, the idea of emotional intelligence is helpful and fashionable in coaching. EI in players and coaches can impact their relationships, their cohesiveness, and their communication to a large extent [9]. The direct association between EI's factors and their results can be effective if the factors and results are properly identified [10].

A meta-analysis study was conducted about the existence of a significant relationship between EI and sports performance that is low in magnitude [11]. Alternatively, trait emotional intelligence is positively connected with athletes' self-governance of motivation [12]. It has also been noted that sports participation, activity, and practice develop EI in athletes, which causes the improvement of sports competencies [13].

The ability [14] and trait [15] are both used to examine emotional intelligence. The ability model of EI is better for the area of practical psychology [16]. On the other hand, the trait model dominates in the study areas that are associated with physical activities and sports [8]. EI illustrates different significances among athletes and non-athletes, and players also have superior interpersonal intelligence that is superior with team sports as opposed to individual sports [17].

People with disabilities have adequate degrees of emotional intelligence with different capacities, which create adapting techniques that empower them to handle trouble [18]. People who are blind from birth have lower EI scores than people who lost their eyesight later in life [19]. For behavior-changing strategies in people with visual impairment, emotional intelligence is an appropriate and good psychological indicator [20].

The interference of EI and goal-setting creates a positive impact on visually impaired people by motivating them to do their work [21]. Students who are not visually impaired are more intelligent regarding controlling their emotions compared to visually impaired students [22]. The range of emotional intelligence of people with visual impairment is mild to moderate, whereas people who are not visually impaired have a moderate EI level. Moreover, people with visual impairments are broad-minded, and ordinary people are mostly maladjusted [23]. Individuals with visual impairment passed through different stages of EI in a different way compared to people with normal vision [24]. Furthermore, it was concluded that controlling emotions, social skills, and understanding emotions have more significant value to the visually impaired athlete. It was observed that athletes with B2 and B3 levels of visual impairment have significantly higher levels of emotional intelligence than visually impaired non-athletes [25]. Hence, provision of sports facilities is mandatory to encourage people with visual impairments. Sports participation and related facilities are mostly the same for people with disabilities and people without disabilities. They participate in sport and physical activities in order to achieve fitness and happiness as well as psychological and social characteristics [26]. Motivations are significant coordinator to increase the intellectual and physical fitness of disabled athletes [26,27]. In many cases, the lack of sports facilities and other hindrances that disabled people encounter stop them from participating in regular sports activities. This leads to rising physical and social problems [28]. In this regard, self-acting and the autonomy of mind can be promoted in these individuals by making rigorous contributions to sports [29].

Physically disabled people will obtain numerous mental and physical fitness advantages if they start participating in sports activities and exercises in their free time [30]. However, to gain fitness benefits and minimize the rate of chronic diseases, people with disabilities should involve in adequate physical activities.

There is not much literature available that supports the fact that visually impaired people are less involved with leisure time physiological workouts and have a more sedentary lifestyle [31-33]. The prevalence of excess body weight and abdominal obesity is more common among visually impaired people [34]. The disturbed BMI level is due to the permanent lack of necessary physical activity of people with visual impairment and blindness [35]. In fact, visually impaired people are not independent enough to acquire 
success and motivation all on their own, which ultimately makes them dependent on society [32]. Several factors are responsible for this assumption, such as low motivation and self-confidence, unsupportive relatives, and other associations [31].

Visually impaired individuals have to understand the significance and the fundamentals of increasing their involvement in physical activities [27]. Furthermore, getting healthy through fun activities and obtaining proper psychological and social acquaintances must be promoted to develop the involvement of people with visual impairment in sports activities.

The positive and negative effects on the performance of athletes are due to many psychological variables [36]. The current effort is to proceed to solve the unanswered psychological factors related to athlete performance, thought, and emotions using different approaches. The concept of emotional intelligence is specifically related to these types of efforts. Presently, emotional intelligence is an emerging idea in sports. In the field of leisure time physical activities, a player's performance and psychology are investigated via emotional factors.

According to the World Health Organization, at least 2.2 billion people in the world suffer from blindness, being near-sighted, or being far-sighted. [37]. The International Blind Sports Federation classified the visually impaired athletes in B1, B2, and B3 categories [38] similar to any other team sports, such as goalball, beep baseball, blind soccer, torball, and floorball. Blind cricket is another combined activity for people with visual impairments [38]. The rules for the visually impaired/blind cricket players are derived from the normal cricket rules with some adjustment according to the disability level. The ball used in blind cricket contains sound-producing tiny carbon balls; an athlete can easily guess the path of the ball because of this [39].

Cricket has been considered as a physical activity of curiosity because it is a group sports activity that is performed passionately in several countries, including Pakistan. Cricket encourages both youth and adults with visual impairments to become strong enough to withstand society in order to attain their needs. Blind cricket assists athletes with visual impairments to gain self-confidence, live independent lives, and help their dependents to achieve excellence with their lives. Youth with visual impairments have the abundant capacity to compete and strive for their personal best and greater achievements in their lives via blind cricket. Cricketers with visual impairment have achieved worldwide recognition. Successful individuals and teams have obtained wide recognition from the community and the government. Blind cricket is turning into a dynamic prospect for visually impaired individuals to examine their talents and skills as well as to develop connections with their peers. It was confirmed that the emotional conditions of the athletes are related to emotional regulation to enhance cricketers' presentation [40]. Cricket is a complex physical activity, and EI is associated with the athlete's presentation [41].

Previous research has consistently shown that an increase in physical activities and sports participation contributes to the enhancement of emotional intelligence in normal people, and limited research has been observed regarding visually impaired athletes in connection with emotional intelligence. To date, as per our knowledge, no research has been conducted to demonstrate that weather, participation in physical activities, and the sport of cricket significantly improve the emotional intelligence of the visually impaired athlete or not. To address that problem, the purpose of the study is to assess the difference in emotional intelligence among visually impaired, blind cricketers, and non-cricketers.

This study assumes that visually impaired athletes who are involved with team sports-cricket in this case-with a more significant level of EI construct more grounded relational connections and are better prepared to lead people more effectively than the visually impaired non-cricketers. In general, they will be richer in their professions and experience better well-being possibilities than athletes with lower EI levels. In the current research study, we also determine the characteristics of the players, the physical activity, and the significance of sociodemographic variables in an account of the EI of the cricketers with visual impairments. 
This research is an effort to disclose and emphasize the relationship of the emotional intelligence levels between cricketers and non-cricketers with visual impairment. The current research will provide awareness to the organizations of the psychological framework of the athletes of a sports team. Furthermore, the current research study supports identifying the behavioral factors of self-control, sociability, well-being, and emotionality among the optimal performers and the low-degree performers. Additionally, this research gives valuable and instructive means for physical instructors, coaches, sports psychologists, and sportspeople to identify with discovering talents, planning, guidance, and preparation of athletes for competition according to their abilities.

\section{Material and Methods}

\subsection{Research Design}

The survey method is a descriptive design that was applied for the present study to differentiate EI among cricketers and non-cricketers who are blind or suffer from visual impairment.

\subsection{Population and Sampling}

In this study, there were 220 participants, which included a mean age of 28.38 and an age range from 18 to 40 years. All of the 220 participants were men who were either visually impaired or blind, including individuals who participated voluntarily. Half of the respondents- -110 respondents with a mean age of 27.81 years and an age range from 18 to 40 years-were recruited from all blind cricket teams from the province Punjab, which is associated with the Pakistan Blind Cricket Council (PBCC), including Attock, Lahore, Gujranwala, Multan, Bahawalpur, Islamabad, Shekhupura, Faisalabad, Okara, and Sargodha. The 110 visually impaired and blind non-cricketers, with included a mean age of 28.95, an SD of 6.012, and an age range from 18 to 40 years, were from the same geographical region as a sample. Purposive sampling was used to select the participants [42]. The EI of the respondents, which included athletes and non-athletes who were blind or suffered from visual impairment, was assessed. The demographic characteristics of the selected sample are shown in Table 1.

Table 1. Demographic characteristic of respondents $(n=220)$.

\begin{tabular}{|c|c|c|c|}
\hline Characteristics & Category & Frequency & Percentage ( $\%)$ \\
\hline \multirow[t]{5}{*}{ Age (in years) } & $16-20$ & 14 & 6.4 \\
\hline & $21-25$ & 58 & 26.4 \\
\hline & $26-30$ & 68 & 30.9 \\
\hline & $31-35$ & 47 & 21.4 \\
\hline & $36-40$ & 33 & 15 \\
\hline \multirow[t]{4}{*}{ Body Mass Index } & $<18.5$ (Underweight) & 7 & 3.2 \\
\hline & 18.5-24.9 (Normal weight) & 126 & 57.3 \\
\hline & 25-29.9 (Overweight) & 84 & 38.2 \\
\hline & $>30$ (Obesity) & 3 & 1.4 \\
\hline \multirow[t]{7}{*}{ Education } & Primary & 6 & 2.7 \\
\hline & Middle & 27 & 12.3 \\
\hline & Matriculation & 71 & 32.3 \\
\hline & Intermediate & 48 & 21.8 \\
\hline & Graduation & 43 & 19.5 \\
\hline & Masters & 23 & 10.5 \\
\hline & MPhil & 2 & 0.9 \\
\hline \multirow[t]{4}{*}{ Experience } & 1-5 Years & 44 & 40 \\
\hline & 6-10 Years & 35 & 31.8 \\
\hline & 11-15 Years & 28 & 25.5 \\
\hline & 16-20 Years & 3 & 2.7 \\
\hline \multirow[t]{4}{*}{ Occupation } & Student & 50 & 25.7 \\
\hline & Un-Employee & 24 & 10.9 \\
\hline & Private-Employee & 49 & 22.3 \\
\hline & Govt-Employee & 97 & 44.1 \\
\hline \multirow[t]{2}{*}{ Social Class } & Poor & 55 & 25 \\
\hline & Middle & 165 & 75 \\
\hline
\end{tabular}




\subsection{Procedure}

Permission from the Pakistan Blind Cricket Council was obtained to contact the participants of the registered clubs of Punjab, which are mentioned above, and to assess the trait EI effect on the athletes and non-athletes who are blind or suffer from visual impairments. Data from the athletes (cricketers) and the non-athletes were collected in the same time frame. All of the team members agreed to participate voluntarily. Almost all of the data were collected using a face-to-face communication method, but some of the data were collected via the telephone because access to the respondents was not possible. First, data were collected from the visually impaired cricketers, and then they were collected from the non-cricketers. The data were collected from July to October 2019. It took approximately $20 \mathrm{~min}$ to complete one interview.

\subsection{Instruments}

A one-to-one interview method was selected to collect the data from all the respondents. The sociodemographic characteristics, a short-form trait emotional intelligence questionnaire, and a short-form international physical activity tool were used to assess the participants. Furthermore, regarding the questionnaires, the scale for the short-form trait emotional intelligence questionnaire (TEIQue-SF) and the international physical activity questionnaire (IPAQ-SF) were printed in Braille and questionnaires were printed with a large font size according to the participants' level of impairment to satisfy the respondents.

\subsubsection{Demographics}

The questionnaire was developed to measure the demographic information of the participants. The demographic information included age, body mass index, playing experience, education level, social status, and occupation.

\section{Body Mass Index}

Maintaining fitness is important for the promotion of health. An increase in physical fitness tends to maintain the appropriate body mass index (BMI) [43]. Hence, a higher BMI leads to lower physical fitness. To calculate the BMI, the heights $(\mathrm{m})$ and weights $(\mathrm{kg})$ of all the respondents were measured. According to the recommendation from $\mathrm{WHO}$, a healthy weight score of the BMI is 18.5 to $24.9\left(\mathrm{~kg} / \mathrm{m}^{2}\right)$, less than $18.5 \mathrm{~kg} / \mathrm{m}^{2}$ is categorized as underweight, and 25 to $29.9\left(\mathrm{~kg} / \mathrm{m}^{2}\right)$ and above $30 \mathrm{~kg} / \mathrm{m}^{2}$ is categorized as overweight, which is considered obese [44].

\subsubsection{Trait Emotional Intelligence}

The questionnaires regarding trait EI originated from [45]. It contains high-quality psychometric items that are associated with sports [8]. The TEIQue-SF provided timesavings as well as concurrent validity and constructive validity. This clarifies that the short form of the trait emotional intelligence questionnaire is an alternating full form [8]. This questionnaire consisted of 30 items that were used to measure EI. These items were derived from the long form of the trait EI questionnaire. Of the 30 items, 26 of the items were allocated to the following four factors: Well-Being (6 items), Emotionality (8 items), Self-Control (6 items), and Sociability (6 items). The remaining four items, which included $3,18,14$, and 29, contributed only to the global trait EI score without any contribution to any specific factors [45]. Every item was evaluated using a seven-point Likert scale, which ranged from (1) completely disagree to (7) completely agree. Cronbach's alpha indicated an excellent internal consistency of the trait EI in the current study, as the value was 0.97, whereas the Cronbach's alpha values of the four factors-Well-Being, Sociability, Emotionality, and Self-Control-were 0.87, 0.87, 0.86, and 0.91, respectively [46]. The Urdu version of the TEIQue-SF was preferred. 


\subsubsection{Physical Activity}

The short form of the self-administered questionnaire, which is called the international physical activity tool, was used to assess the last 7 days [47] of physical activities of the visually impaired athletes, the blind athletes, and the non-athletes. The IPAQ-SF recorded the four levels of intensities, which included vigorous Physical Intensity (PI), moderate Physical Intensity, walking, and sitting. The total number of days and the time, which was recorded in minutes, of the physical activity was calculated using the IPAQ-SF scoring system from the IPAQ website. The obtained metabolic equivalent (MET-min/week scores) from the raw data and the three categories, which included low, moderate, and high, were used for the data analysis.

\subsection{Data Analysis}

110 visually impaired and blind cricket players from registered teams in the Punjab province along with the 110 non-players completed the survey. The data was successfully collected, and it was used for further statistical analysis. The rationale of the current study, the descriptive statistics, a frequency analysis, varimax rotation analysis of the questionnaire, a $t$-test, and the correlation analytical techniques were applied using the statistical software SPSS version 25 .

\subsection{Ethical Consideration}

Prior to conducting the experiments, full disclosure about the purpose of the study was given before written consent was obtained from each of the participants. The contribution to this research was unpaid, and the researchers are responsible to keep the data confidential. The psychological evaluation forms of respondents were and will only be used for study purposes.

\section{Results}

3.1. Demographic Data of the Respondents:

The data that were collected from the demographic data sheet are discussed below.

\subsubsection{Age}

The ages of respondents were categorized into groups. After the analysis of the data, the mean age of the athletes was 28 years. Figure 1 shows the age categories of the sample $(n=110)$ in a pie chart. The majority of the visually impaired cricketers from Punjab are between 26 and 30 years of age.

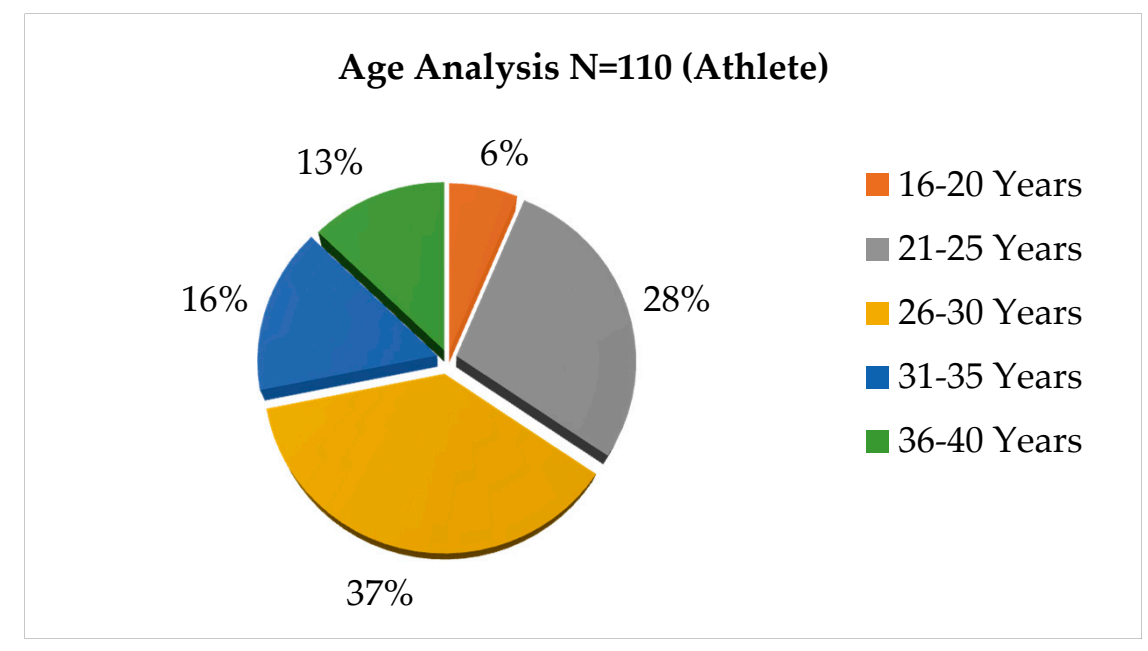

Figure 1. Analysis of the age of athletes. $(n=110)$. 


\subsubsection{Body Mass Index (BMI)}

The sample ( $n=110$ ) was categorized into four groups according to the respondents' body mass indices. The categories of less than $18 \mathrm{~kg} / \mathrm{m}^{2}, 18-24.9 \mathrm{~kg} / \mathrm{m}^{2}, 25-29.9 \mathrm{~kg} / \mathrm{m}^{2}$, and equal to and above $30 \mathrm{~kg} / \mathrm{m}^{2}$ are labeled as underweight, normal weight (healthy), overweight, and obese as shown in Figure 2. All the teams from the Punjab province mainly consisted of healthy weighted players.

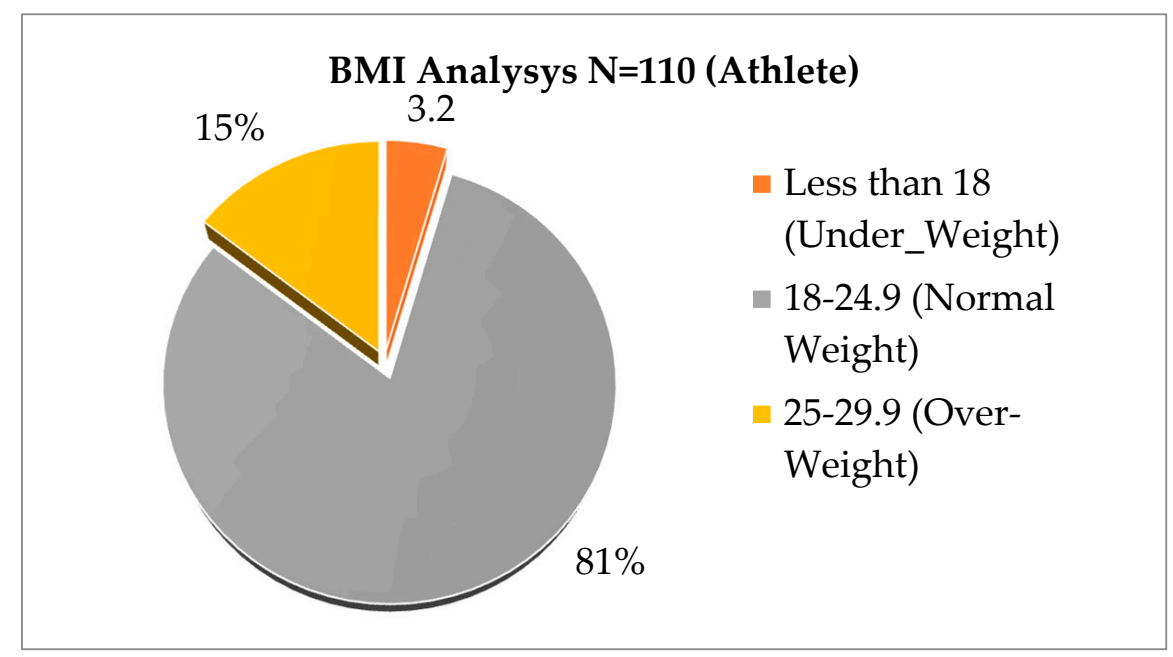

Figure 2. Analysis of the body mass index of the athletes. $(n=110)$.

Alternatively, the majority of the visually impaired/blind samples of the non-cricketers from Punjab are overweight, even though $33 \%$ of the non-cricketers have a healthy weight. Most blind and visually impaired people prefer to walk during their normal routines, so a small percentage of these peoples are obese, which is shown in Figure 3.

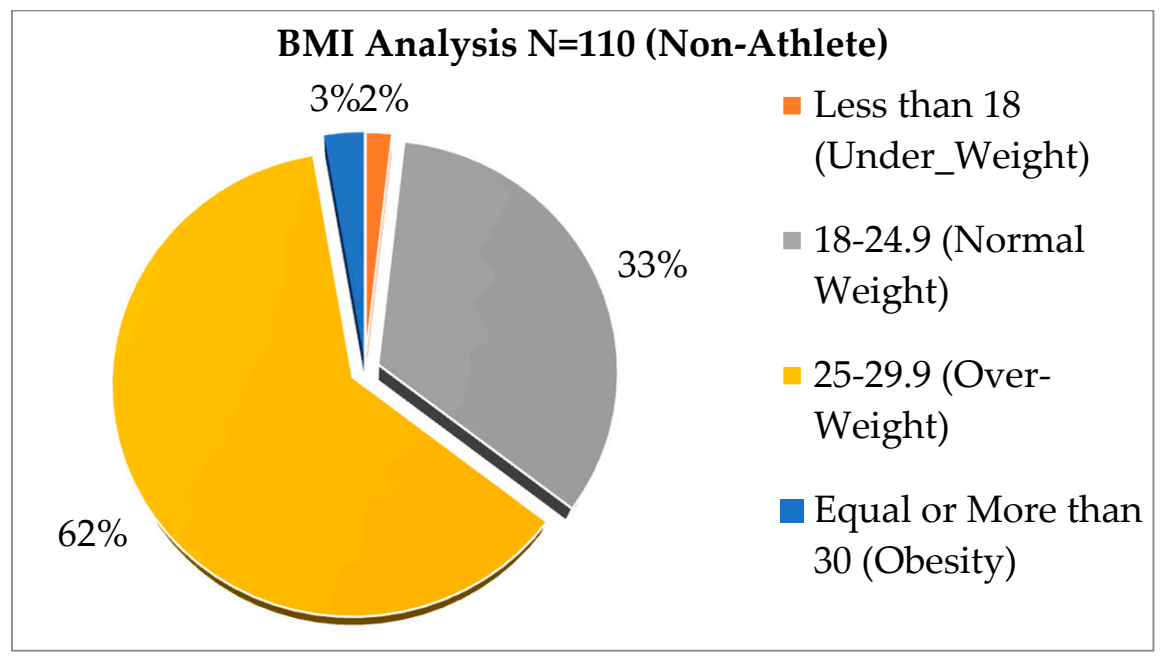

Figure 3. Analysis of the body mass index of non-athletes. $(n=110)$.

\subsubsection{Education}

Figure 4 displays the education levels of the visually impaired/blind cricketers from the Punjab teams. The sample is categorized according to the qualifications from the primary level to the MPhil level. Most of the players are educated up to the secondary level. There is an equal number of graduates and masters. Education for people with disabilities is free in Pakistan. Due to a $3 \%$ job quota according to the Punjab government [48], visually impaired athletes try to obtain good qualifications to acquire a job. 


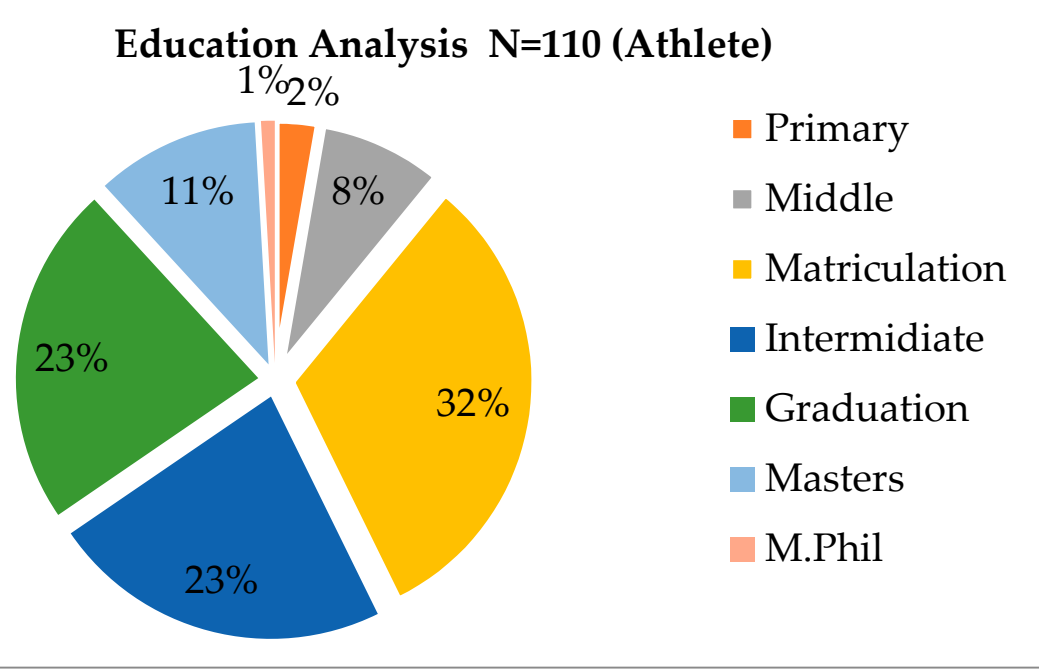

Figure 4. Analysis of the educational qualification of the athletes. $(n=110)$.

\subsubsection{Occupation}

Occupations of the visually impaired athletes were categorized into four groups, as shown in Figure 5. According to the most recent results regarding educational qualifications, it is noticeable that most of the cricketers have a government job, whether it is a regular job, a contract job, or a or daily wage basis job.

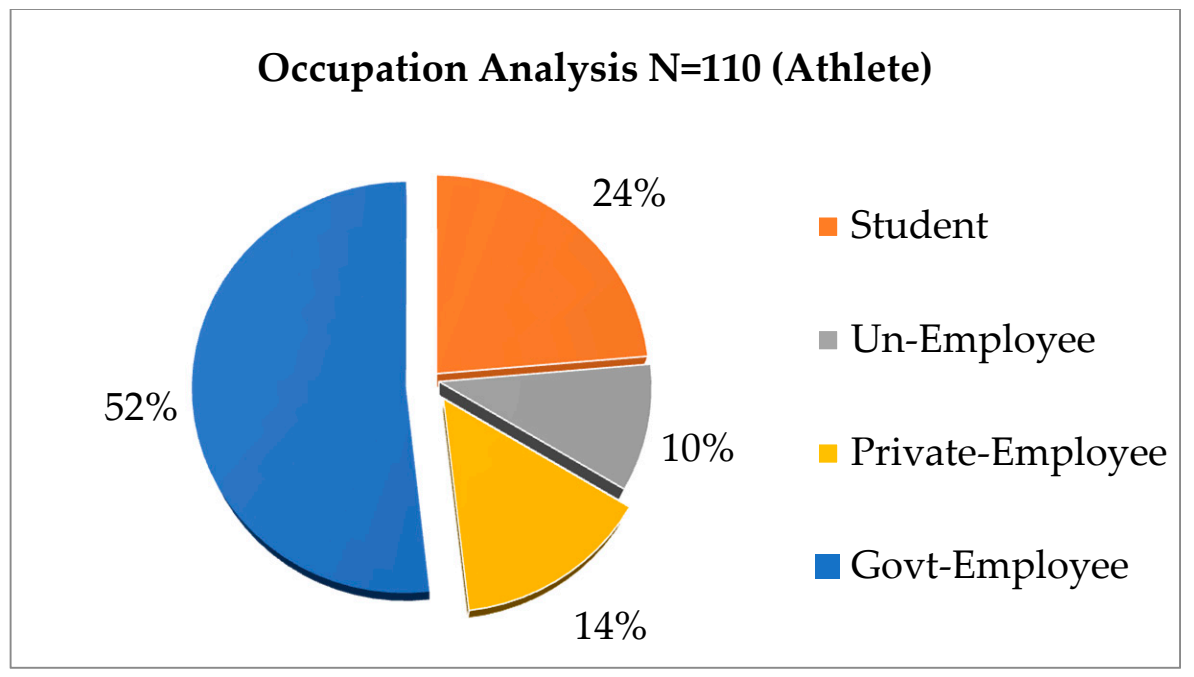

Figure 5. Analysis of occupation of the athletes. $(n=110)$

\subsubsection{Experience}

The playing experience of the visually impaired athletes was categorized into four groups. After the analysis of the data, the mean concerning the experience of the athletes is 7.5 years. According to the pie graph, $40 \%$ of the total athletes from the Punjab cricket teams have 1 to 5 years of experience playing cricket, whereas only $3 \%$ have more than 16 years of experience playing cricket as shown in Figure 6.

\subsubsection{Social Class}

The social class of the sample was categorized into poor, middle, and rich classes. Figure 7 displays that the majority of the athletes belonged to a middle-class family, and $15 \%$ of the visually impaired cricketers from Punjab's teams belonged to a poor class family. Not one single visually impaired athlete belonged to the wealthy class. 


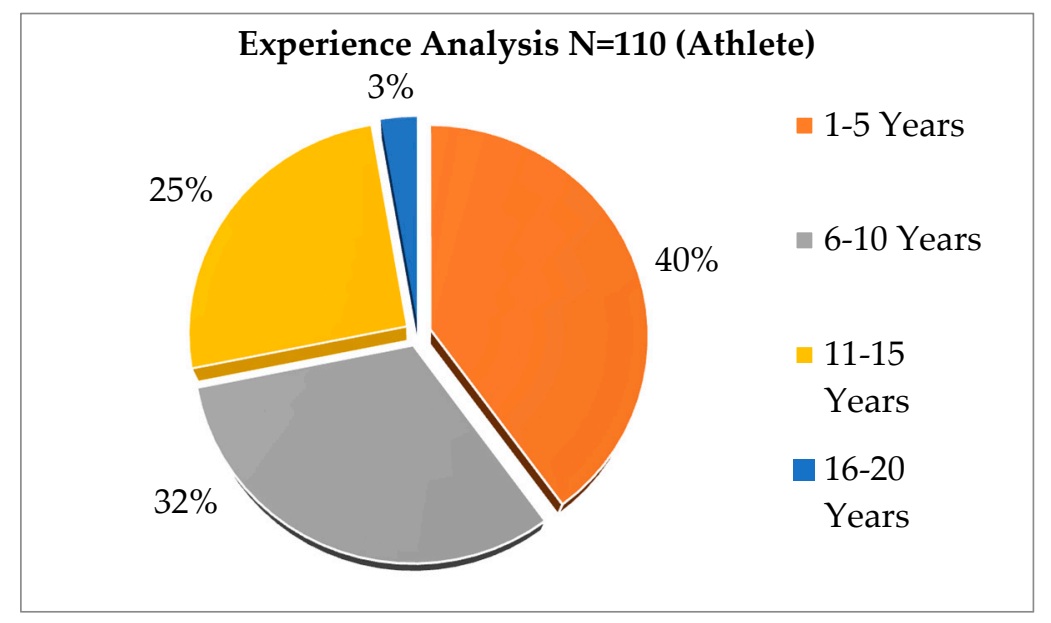

Figure 6. Analysis of the playing experience of the athletes. $(n=110)$

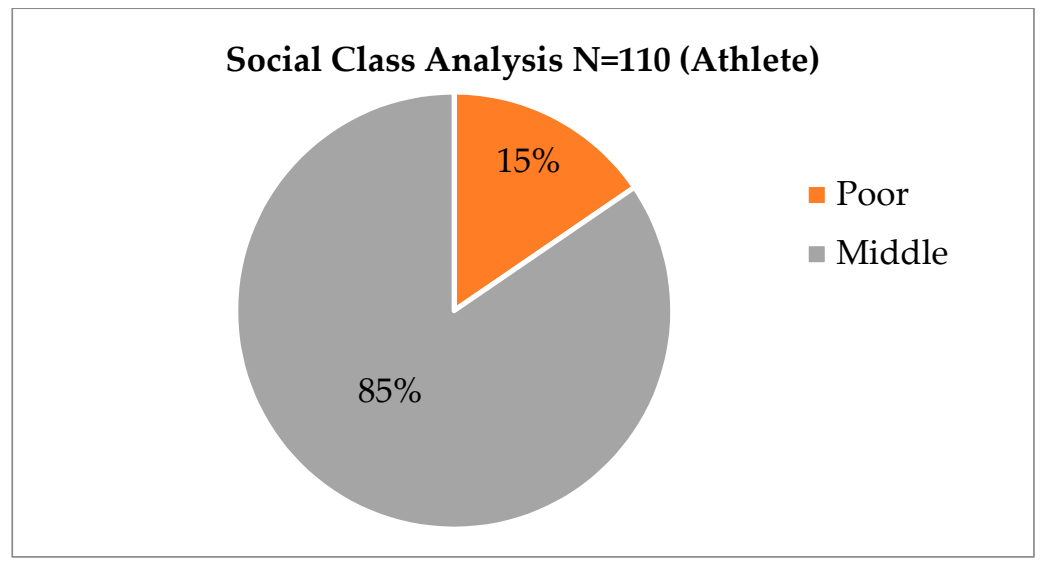

Figure 7. Analysis of the social class of the athlete. $(n=110)$

\subsection{T-Test, Varimax Rotation and Correlation Analyses}

An independent sample $t$-test was performed to compare the means of the trait EI, the athletes, and the non-athletes. The test illustrated a significant difference between the athletes versus the non-athletes' $t(194.914)=59.099$ and $\rho=0.01(<0.05)$. The athletes group showed a significantly higher score $(\mathrm{M}=6.199$ and $\mathrm{SD}=0.1931)$ on the measure of the global trait EI than from the participants in the non-athletic group $(\mathrm{M}=4.299$ and $\mathrm{SD}=0.2764)$. The analysis further indicated that the effect was larger than expected $(r=0.97)$ [49]. The group statistics are shown in Table 2.

Table 2. Group Statistics

\begin{tabular}{cccccc}
\hline & $\begin{array}{c}\text { Athletes } \\
\text { Non-Athletes }\end{array}$ & N & Mean & Std. Deviation & Std. Error Mean \\
\hline \multirow{2}{*}{ Total Trait EI } & Athletes & 110 & 6.199 & 0.1931 & 0.0184 \\
& Non-Athletes & 110 & 4.299 & 0.2764 & 0.0264 \\
\hline
\end{tabular}

A principal component analysis was conducted on 26 items through orthogonal rotation (Varimax). Four items-3, 18, 14, and 29-were excluded from the PCA because it was considered as a general or auxiliary factor as described in methodology [45]. Thus, they are not specially connected with any certain factor. The remaining 26 items were analyzed. The Kaiser-Meyer-Olkin measure (KMO) proved that sampling suitability for the analysis is equal to 0.97 , which is fit above the satisfactory limit of 0.5 [50]. Bartlett's test 
of sphericity was $\chi^{2}(325)=5458.014 . p<0.001$ shows that the correlation among items was significantly large for PCA. An initial analysis was performed to acquire the eigenvalue of respective components in the data. Four components have an eigenvalue of Kaiser certain of 1 and collectively explained $70.1 \%$ of the variance. The scree plot shown in Figure 8 showed that a one-factor solution best fit the data. Table 3 shows the factor loading after varimax rotation; all extracted factor loadings are greater than 0.41 , ranging from 0.47 to 0.89 . The item on the group on the same components suggests that component 1 represents well-being, component 2 represents self-control, component 3 represents emotionality, and component 4 represents sociability.

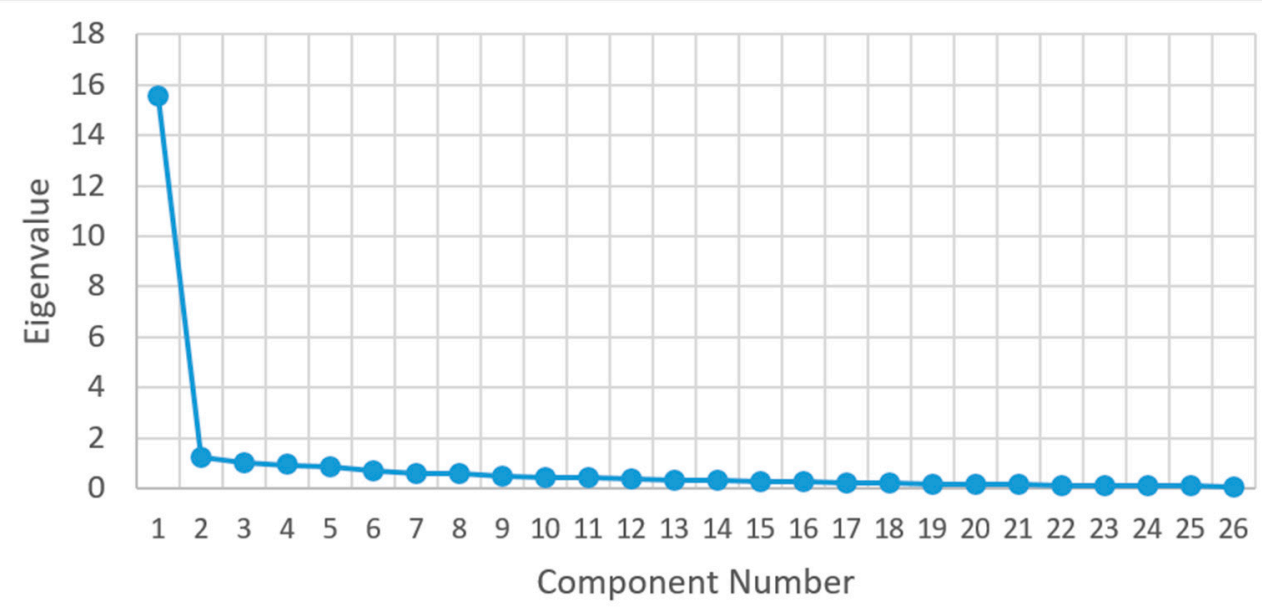

Figure 8. The scree plot of the short-form trait emotional intelligence questionnaire (TEIQue-SF) after Varimax rotation.

The trait EI $(\mathrm{M}=5.251$ and $\mathrm{SD}=0.9834)$ and the BMI $(\mathrm{M}=2.38$ and $\mathrm{SD}=0.572)$ showed a significant moderate negative correlation between them $(r(220)=-0.466$ and $\rho<0.001)$. The playing cricket experience $(\mathrm{M}=3.74$ and $\mathrm{SD}=4.8)$ and the trait $\mathrm{EI}(\mathrm{M}=5.251$ and $\mathrm{SD}=0.9834)$ displayed a significant strong positive relationship between them $(r(220)=0.758$ and $\rho<0.001)$. Pearson correlation's result indicated a significant strong positive correlation exists among the trait $\mathrm{EI}(\mathrm{M}=5.251$ and $\mathrm{SD}=0.9834)$ and the total physical activity (PA) (MET-min/week) $(\mathrm{M}=2.38, \mathrm{SD}=0.689 ; r(220)=0.849$ and $\rho<0.001)$. The sedentary activity $(\mathrm{M}=4.0214$ and $\mathrm{SD}=1.16707)$ and the trait $\mathrm{EI}(\mathrm{M}=5.251$ and $\mathrm{SD}=0.9834)$ indicated a significantly strong negative correlation with each other $(r(220)=-0.719$ and $\rho<0.01)$. The total PA (MET-min/week) $(\mathrm{M}=2.38$ and $\mathrm{SD}=0.689)$ displayed a significant strong positive relationship with playing experience $(\mathrm{M}=3.74$ and $\mathrm{SD}=4.8 ; r(220)=0.702$ and $\rho<0.001)$ and a significant moderate negative relationship with the BMI $(\mathrm{M}=2.38$ and $\mathrm{SD}=0.572 ; r(220)=-0.483$ and $\rho<0.001)$. The body mass index $(\mathrm{M}=2.38$ and $\mathrm{SD}=0.572)$ had a significant positive relation with the sedentary behavior (inactivity) $(\mathrm{M}=4.0214$ and $\mathrm{SD}=1.16707) r(220)=0.443$ and $\rho<0.001$. The analysis further indicated that there is no significant difference between age $(\mathrm{M}=28.28$ and $\mathrm{SD}=5.638)$ and emotional intelligence $(\mathrm{M}=5.251$ and $\mathrm{SD}=0.9834)$.

Furthermore, the correlation analyses also indicated a positive strong correlation among the four factors of the trait EI: Well-Being $(M=5.4295$ and $S D=1.01920)$, Sociability $(\mathrm{M}=5.0432$ and $\mathrm{SD}=1.13387)$, Emotionality $(\mathrm{M}=5.4011$ and $\mathrm{SD}=0.80622)$, and Self-Control $(\mathrm{M}=5.0879$ and $\mathrm{SD}=1.10674)$.

Table 4 displays the descriptive statistics, the alpha coefficient, and Pearson correlation matrix of the variables. 
Table 3. Factor loadings after Varimax rotation of TEIQue-SF.

\begin{tabular}{|c|c|c|c|c|}
\hline \multicolumn{5}{|l|}{ Rotated Component Matrix } \\
\hline \multirow{2}{*}{ Item } & \multicolumn{4}{|c|}{ Component } \\
\hline & Well-Being & Self-Control & Emotionality & Sociability \\
\hline I'm usually able to find ways to control my emotions when I want to & 0.89 & 0.25 & 0.04 & 0.12 \\
\hline On the whole, I'm able to deal with stress. & 0.86 & 0.32 & -0.02 & 0.08 \\
\hline $\begin{array}{l}\text { I'm normally able to "get into someone's shoes" and experience } \\
\text { their emotions. }\end{array}$ & 0.84 & 0.29 & -0.01 & -0.04 \\
\hline On the whole, I'm pleased with my life. & 0.81 & 0.19 & -0.04 & 0.09 \\
\hline I don't seem to have any power at all over other people's feelings. & 0.65 & 0.28 & 0.05 & 0.12 \\
\hline I'm usually able to influence the way other people feel. & 0.64 & 0.30 & -0.17 & 0.10 \\
\hline I often find it difficult to stand up for my rights. & 0.62 & 0.20 & 0.09 & 0.13 \\
\hline I would describe myself as a good negotiator. & 0.62 & 0.36 & -0.10 & 0.04 \\
\hline $\begin{array}{l}\text { I often find it difficult to adjust my life according to the } \\
\text { circumstances. }\end{array}$ & 0.53 & 0.35 & 0.03 & 0.17 \\
\hline I can deal effectively with people. & 0.41 & 0.14 & -0.05 & -0.03 \\
\hline I often pause and think about my feelings. & 0.38 & 0.79 & -0.03 & -0.08 \\
\hline Expressing my emotions with words is not a problem for me. & 0.8 & 0.65 & 0.09 & 0.06 \\
\hline I generally don't find life enjoyable. & 0.34 & 0.57 & 0.19 & 0.06 \\
\hline I generally believe that things will work out fine in my life. & 0.13 & 0.51 & -0.13 & -0.03 \\
\hline On the whole, I have a gloomy perspective on most things. & 0.23 & 0.43 & 0.07 & 0.18 \\
\hline $\begin{array}{l}\text { I'm normally able to "get into someone's shoes" and experience } \\
\text { their emotions. }\end{array}$ & 0.25 & 0.18 & 0.73 & 0.19 \\
\hline I believe I'm full of personal strengths. & 0.31 & 0.37 & 0.67 & 0.08 \\
\hline Others admire me for being relaxed. & -0.25 & -0.03 & 0.64 & 0.11 \\
\hline I often find it difficult to show my affection to those close to me. & 0.12 & -0.06 & 0.53 & -0.04 \\
\hline I feel that I have a number of good qualities. & 0.34 & 0.38 & 0.49 & -0.08 \\
\hline On the whole, I have a gloomy perspective on most things. & 0.28 & 0.16 & 0.42 & -0.14 \\
\hline Those close to me often complain that I don't treat them right. & 0.28 & 0.38 & -0.34 & 0.65 \\
\hline I find it difficult to bond well even with those close to me. & 0.16 & -0.04 & 0.14 & 0.63 \\
\hline I tend to get involved in things I later wish I could get out of. & 0.22 & 0.32 & -0.03 & 0.59 \\
\hline Many times, I can't figure out what emotion I'm feeling. & -0.05 & 0.06 & 0.30 & 0.50 \\
\hline I tend to "back down" even if I know I'm right. & 0.08 & 0.05 & -0.18 & 0.47 \\
\hline Eigenvalue & 15.539 & 1.342 & 1.201 & 1.045 \\
\hline$\%$ of variance & 59.77 & 4.48 & 3.48 & 3.27 \\
\hline
\end{tabular}

Note: Factor loadings over 0.40 appear in bold.

Table 4. Descriptive statistics, alpha coefficient, and Pearson correlation matrix between the different variables $(n=220)$.

\begin{tabular}{|c|c|c|c|c|c|c|c|c|c|c|c|c|c|c|}
\hline & & $\mathbf{M}$ & SD & $\alpha$ & 1 & 2 & 3 & 4 & 5 & 6 & 7 & 8 & 9 & 10 \\
\hline 1 & Age & 28.38 & 5.638 & - & - & & & & & & & & & \\
\hline 2 & $\begin{array}{l}\text { Body Mass } \\
\text { Index }\end{array}$ & 2.38 & 0.572 & - & $0.436^{* *}$ & - & & & & & & & & \\
\hline 3 & Experience & 3.74 & 4.800 & - & $0.219^{* *}$ & $-0.339 * *$ & - & & & & & & & \\
\hline 4 & $\begin{array}{c}\text { Total PA } \\
\text { (MET- } \\
\text { min/week) }\end{array}$ & 2.38 & 0.689 & - & $-0.143^{* *}$ & $-0.483^{* *}$ & 0.702 ** & - & & & & & & \\
\hline 5 & $\begin{array}{l}\text { Sedentary } \\
\text { Activity }\end{array}$ & 4.0214 & 1.16707 & - & 0.106 & 0.443 ** & $-0.604 * *$ & $-0.719 * *$ & - & & & & & \\
\hline
\end{tabular}


Table 4. Cont.

\begin{tabular}{|c|c|c|c|c|c|c|c|c|c|c|c|c|c|c|}
\hline & & M & SD & $\alpha$ & 1 & 2 & 3 & 4 & 5 & 6 & 7 & 8 & 9 & 10 \\
\hline 6 & $\begin{array}{c}\text { Global Trait EI } \\
\text { Score }\end{array}$ & 5.249 & 0.9815 & 0.97 & -0.063 & $-0.465^{* *}$ & $0.759 * *$ & $0.849 * *$ & $-0.719 * *$ & - & & & & \\
\hline 7 & Well-Being & 5.4242 & 1.01389 & 0.87 & -0.046 & $-0.435^{* *}$ & $0.746^{* *}$ & $0.801^{* *}$ & $-0.683^{* *}$ & $0.964^{* *}$ & - & & & \\
\hline 8 & Sociability & 5.0479 & 1.13256 & 0.87 & -0.065 & $-0.426^{* *}$ & $0.719 * *$ & $0.803^{* *}$ & $-0.678^{* *}$ & $0.961^{* *}$ & $0.904 * *$ & - & & \\
\hline 9 & Emotionality & 5.4011 & 0.80622 & 0.86 & -0.069 & $-0.448^{* *}$ & $0.709 * *$ & 0.790 ** & $-0.683^{* *}$ & $0.942 * *$ & $0.898^{* *}$ & $0.874^{* *}$ & - & \\
\hline 10 & Self-Control & 5.0886 & 1.10765 & 0.91 & -0.055 & $-0.447^{* *}$ & 0.733 ** & $0.843^{* *}$ & $-0.716^{* *}$ & $0.964^{* *}$ & $0.906^{* *}$ & $0.917^{* *}$ & $0.863 * *$ & - \\
\hline
\end{tabular}

** Correlation is significant at the 0.01 level (2-tailed).

\section{Discussion}

The rationale of the current research was to assess the trait emotional intelligence among the visually impaired athletes and the non-athletes based on their characteristics, which included demographic and some socioeconomic variables. According to this research, the global trait EI of the athletes and the non-athletes are significantly different from each other. Specifically, the visually impaired athletes appeared to have a high score in EI than the non-athletes. The results of the factor analysis maintained the use of the four-factor structure reported by the TEIQue-SF; all extracted factor loadings were acceptable. The result shows the explained variance value is 70.04; earlier, it was recorded that the explained value of more than $60 \%$ in social science is considered acceptable [51]. The Kaiser-Meyer-Olkin measure shown a superb value of 0.97 and fit above the satisfactory limit of 0.5 [50]. The first factor derived from factor analysis with varimax rotation was well-being, followed by self-control, emotionality, and sociability, in sequence [45].

The current study describes the significant relationship between physical activity and emotional intelligence. The result was recorded earlier in the systematic research, in which the researchers reviewed all the cross-sectional studies, whereas only one available longitudinal study regarding the strong relationship between EI and physical activity was available [13]. Furthermore, the findings showed that the subscale of the trait EI-the factors well-being, sociability, emotionality, and self-control—shows a strong significant relationship among all the variables and the global trait EI as well. It also showed a higher score from the visually impaired athletes than the non-athletes. It was previously demonstrated that there is a difference in the scores among the subscales of the athletes and the non-athletes [52-54]. The findings were strengthened by a few further studies, which described that the visually impaired athletes and the non-athletes had a significant difference in the psychological factors, which included socialization [55], well-being [56,57], and motivation [58].

This study further yields that EI and work experience have a significant positive correlation with each other. The result is in line with the research, which observed that an increase in work experience tends to increase emotional intelligence [59]. Moreover, experience provides better EI for visually impaired athletes as compared to non-athletes.

The current study also explained that no significant relationship existed between emotional intelligence and the age of the visually impaired respondents as opposed to experience. The study proved that age does not matter with regard to increasing or decreasing emotional intelligence without controlling other factors along with the four factors of EI. The findings are consistent with the findings from the authors of [59] and [60], who concluded in their research that age has an insignificant relationship with emotional intelligence $[59,60]$.

The finding illustrated that inactivity of the visually impaired athletes and the nonathletes, which is expressed as a sedentary activity, has a significant negative correlation with the global score of trait emotional intelligence. It also has a potential positively significant correlation with the BMI, as it was shown that an increase in the BMI is due to an increase in the inactivity time of the visually impaired respondents. Similar results in EI among the active and the non-active visually impaired individuals observed that the active individuals proved to have better EI [54,61]. Physical activity prevents metabolic syndrome, so the sedentary lifestyle with long sitting time is only connected to obesity [62]. 


\section{Limitations of the Study}

In the study, the first limitation was the selection of the short form of the trait emotional intelligence questionnaire to administrate the sample. Alternatively, the long form of the TEIQue gave more appropriate findings along with facets. Due to a shortage of time and the use of physical activity tools along with the demographic data, the short form was considered. Additionally, the restriction of the current research was the collection medium of the data. Our target was to collect all the data using face-to-face communication. However, due to some unreachable individuals, the data was collected via the telephone. During the collection of the data, the researcher faced hesitations from some of the visually impaired respondents regarding answering some of the questions. Providing brief instructions about the type and reasons of tools that are used is essential before administering the questionnaire.

The major limitation of the research was the shortage of research literature regarding visually impaired athletes and the trait emotional intelligence. To overcome these limitations, further studies are suggested in this field.

\section{Conclusions}

We determined from the significant difference of EI among athletes and non-athletes that trait emotional intelligence of the athlete with visual impairment is greater than the non-athlete with visual impairment or blindness; it enables them to recognize, review, and control their own emotions and ability to understand and respond to the emotions of others. Visually impaired cricketers can more effectively regulate their relationships with others. Through the current research, it is suggested that the trait EI among the visually impaired people is enhanced due to participating in physical and sporting activities that additionally boost the physical fitness of the individuals. Through the discussion, it is concluded that participation in sports and physical activities boosts the emotional intelligence of people with visual impairments. Furthermore, it is concluded that EI has a significant relationship with the sports playing experience, sports participation, and physical activity, and it has an inverse relationship with inactivity, which is a sedentary lifestyle, and the body mass index; the age of the individuals is insignificant.

It is suggested that a longitudinal study should be administered with athletes who have visual impairments or blindness to uncover the causes of the changes in emotional intelligence and its effect on the visually impaired sports teams or individuals. It is recommended that the use of different statistical populations of visually impaired athletes should be conducted to compare emotional intelligence with other psychological variables in future research. Furthermore, it is important to create private and government avenues to provide more physical activities and team sports programs for the visually impaired people and essential training programs to support understanding emotions. Due to such programs, the performance of the visually impaired individuals' well-being can be improved at a low cost.

Author Contributions: Conceptualization, S.H. and A.A.; methodology, S.H. and A.A.; software, S.H. and A.A.; validation, J.H.; formal analysis, S.H. and A.A.; investigation, S.H. and A.A.; resources, J.H.; data curation, S.H. and A.A.; writing-original draft preparation, S.H., A.A., Y.G.C., and J.H.; writing-review and editing, Y.G.C. and J.H. All authors have read and agreed to the published version of the manuscript.

Funding: This research received no external funding.

Institutional Review Board Statement: Not applicable.

Informed Consent Statement: Not applicable.

Data Availability Statement: Data sharing not applicable.

Conflicts of Interest: The authors declare no conflict of interest. 


\section{References}

1. Williams, L.E.; Bargh, J.A.; Nocera, C.C.; Gray, J.R. The unconscious regulation of emotion: Nonconscious reappraisal goals modulate emotional reactivity. Emotion 2009, 9, 847-854. [CrossRef]

2. Salovey, P.; Mayer, J.D. Emotional Intelligence. Imagin. Cogn. Personal. 1990, 9, 185-211. [CrossRef]

3. Goleman, D. EI: Why It Can Matter More than IQ; Bloomsbury: London, UK, 1995.

4. Cotruş, A.; Stanciu, C.; Bulborea, A.A. EQ vs. IQ Which is Most Important in the Success or Failure of a Student? Procedia Soc. Behav. Sci. 2012, 46, 5211-5213. [CrossRef]

5. Stough, C.; Saklofske, D.H.; Parker, J.D.A. A Brief Analysis of 20 Years of Emotional Intelligence: An Introduction to Assessing Emotional Intelligence: Theory, Research, and Applications. In Handbook of Individual Differences in Cognition; Springer International Publishing: Cham, Switzerland, 2009; pp. 3-8.

6. Jones, M.V. Controlling Emotions in Sport. Sport Psychol. 2003, 17, 471-486. [CrossRef]

7. Lazarus, R.S. How Emotions Influence Performance in Competitive Sports. Sport Psychol. 2000, 14, 229-252. [CrossRef]

8. Laborde, S.; Dosseville, F.; Allen, M.S. Emotional intelligence in sport and exercise: A systematic review. Scand. J. Med. Sci. Sports 2015, 26, 862-874. [CrossRef]

9. Hwang, S.; Feltz, D.L.; Lee, J.-D. Emotional intelligence in coaching: Mediation effect of coaching efficacy on the relationship between emotional intelligence and leadership style. Int. J. Sport Exerc. Psychol. 2013, 11, 292-306. [CrossRef]

10. Barlow, A.; Banks, A.P. Using emotional intelligence in coaching high-performance athletes: A randomised controlled trial. Coach. Int. J. Theory Res. Pract. 2014, 7, 132-139. [CrossRef]

11. Kopp, A.; Jekauc, D. The Influence of Emotional Intelligence on Performance in Competitive Sports: A Meta-Analytical Investigation. Sports 2018, 6, 175. [CrossRef]

12. Sukys, S.; Tilindienè, I.; Cesnaitiene, V.J.; Kreivyte, R. Does Emotional Intelligence Predict Athletes' Motivation to Participate in Sports? Percept. Mot. Ski. 2019, 126, 305-322. [CrossRef]

13. Ubago-Jiménez, J.L.; González-Valero, G.; Puertas-Molero, P.; García-Martínez, I. Development of Emotional Intelligence through Physical Activity and Sport Practice. A Systematic Review. Behav. Sci. 2019, 9, 44. [CrossRef]

14. Mayer, J.D.; Caruso, D.R.; Salovey, P. Emotional intelligence meets traditional standards for an intelligence. Intelligence 1999, 27, 267-298. [CrossRef]

15. Petrides, K. V Trait Emotional Intelligence Theory. Ind. Organ. Psychol. 2010, 3, 136-139. [CrossRef]

16. Fletcher, T.B. Emotional Intelligence: A Theoretical Overview and Implications for Research and Professional Practice in Sport Psychology AU- Meyer, Barbara B. J. Appl. Sport Psychol. 2007, 19, 1-15. [CrossRef]

17. Saklofske, D.H.; Austin, E.J.; Rohr, B.A.; Andrews, J.J. Personality, Emotional Intelligence and Exercise. J. Health Psychol. 2007, 12, 937-948. [CrossRef]

18. Díaz, M.G.; García, M.J. Emotional Intelligence, Resilience and Self-Esteem in Disabled and Non-Disabled People. Enferm. Global 2018. [CrossRef]

19. Parween, S. Variables Influencing Emotional Intelligence of Visually Impaired Students in Higher Education. Disabil. CBR Incl. Dev. 2015, 26, 97-108. [CrossRef]

20. Eniola, M.S. The Influence of Emotional Intelligence and Self-Regulation Strategies on Remediation of Aggressive Behaviours in Adolescent with Visual Impairment. Stud. ETHNO-Med. 2007, 1, 71-77. [CrossRef]

21. Eniola, M.S.; Adebiyi, K. Emotional intelligence and goal setting-An investigation into interventions to increase motivation to work among visually impaired students in Nigeria. Br. J. Vis. Impair. 2007, 25, 249-253. [CrossRef]

22. Sushil, K.; Jagat, S. Emotional Intelligence and Adjustment Among Visually Impaired and Sighted School Students. Asian J. Multidimens. Res. 2013, 2, 1-8.

23. Mirzaei, S.; Saeedi, R. Comparison of Emotional Intelligence and Personality Traits of the Successful and Normal Indi-vidual with Visual Impairments in Tehran City. Int. J. Appl. Psychol. 2013, 3, 83-87. [CrossRef]

24. Rostami, R.; Mohammadi, N. A Comparative Study on Emotional Intelligence and Mental Toughness for Visually Impaired Male and Female Athletes. Int. J. Kinesiol. Sports Sci. 2015, 3, 74-78. [CrossRef]

25. Dalbudak, I. 18-20 Yas Arasi Spor Yapan ve Yapmayan B2 ve B3 Görme Engelli Bireylerin Duygusal Zeka ve Saldirganlik Düzeyleri; Gece Kitapligi: Ankara, Turkey, 2020.

26. Kampfe, A.; Honer, O.; Willimczik, K. Multiplicity and Development of Achievement Motivation: A Comparative Study between German Elite Athletes with and without a Disability. Eur. J. Adapt. Phys. Act. 2014, 7, 32-48. [CrossRef]

27. Jaarsma, E. Sports Participation and Physical Disabilities: Taking the Hurdle. Ph.D. Thesis, University of Groningen, Groningen, The Netherlands, 2014.

28. Jaarsma, E.A.; Geertzen, J.H.B.; de Jong, R.; Dijkstra, P.U.; Dekker, R. Barriers and Facilitators of Sports in Dutch Paralympic Athletes: An Explorative Study. Scand. J. Med. Sci. Sports 2014, 24, 830-836. [CrossRef]

29. Kalyvas, V.; Reid, G. Sport Adaptation, Participation, and Enjoyment of Students with and without Physical Disabilities. Adapt. Phys. Activ. Q. 2003, 20, 182-199. [CrossRef]

30. Carroll, D.D.; Courtney-Long, E.A.; Stevens, A.C.; Sloan, M.L.; Lullo, C.; Visser, S.N.; Fox, M.H.; Armour, B.S.; Campbell, V.A.; Brown, D.R.; et al. Vital Signs: Disability and Physical Activity-United States, 2009-2012. MMWR. Morb. Mortal. Wkly. Rep. 2014, 63, 407-413. [PubMed] 
31. Augestad, L.B.; Jiang, L. Physical activity, physical fitness, and body composition among children and young adults with visual impairments: A systematic review. Br. J. Vis. Impair. 2015, 33, 167-182. [CrossRef]

32. Lieberman, L.J.; Byrne, H.; Mattern, C.O.; Watt, C.A.; Fernández-Vivó, M. Health-Related Fitness of Youths with Visual Impairments. J. Vis. Impair. Blind. 2010, 104, 349-359. [CrossRef]

33. Longrnuir, P.E. Factors Influencing the Physical Activity Levels of Youths with Physical and Sensory Disabilities. Adapt. Phys. Act. Q. 2000, 17, 40-53.

34. Magdalena, W.; Urzedowicz, B.; Motylewski, S.; Zeman, K.; Pawlicki, L. Body mass index and waist-to-height ratio among schoolchildren with visual impairment. Medicine 2016, 95, e4397. [CrossRef] [PubMed]

35. Vági, Z.; Dee, K.; Lelovics, Z.; Lakatos, É. Nutritional status of blind and visually impaired patients. Z. Gastroenterol. 2012, 50. [CrossRef]

36. Ashwani Bali Psychological Factors Affe Cting Sports Performance. Int. J. Phys. Educ. Sports Health 2015, 1, 92-95.

37. World Health Organization. World Report on Vision; WHO Press: Geneva, Switzerland, 2019; ISBN 978-92-4-151657-0.

38. IBSA. IBSA Classification Rules and Procedures; IBSA: Parsippany, NJ, USA, 2011; p. 23.

39. Varyo, T.; Guttridge, T. The World Blind Cricket Council International Playing Rules; World Blind Cricket Council: Bengaluru, India, 2005; pp. 1-7.

40. Totterdell, P.; Leach, D. Negative mood regulation expectancies and sports performance: An investigation involving professional cricketers. Psychol. Sport Exerc. 2001, 2, 249-265. [CrossRef]

41. Crombie, D.; Lombard, C.; Noakes, T. Emotional Intelligence Scores Predict Team Sports Performance in a National Cricket Competition. Int. J. Sports Sci. Coach. 2009, 4, 209-224. [CrossRef]

42. Mills, G.E.; Gay, L.R. Educational Research: Competencies for Analysis and Applications, Global Edition; Pearson Education Limited: London, UK, 2015; ISBN 9781292106205.

43. Nikolaidis, P.T.; Ingebrigtsen, J. The relationship between body mass index and physical fitness in adolescent and adult male team handball players. Indian J. Physiol. Pharmacol. 2014, 57, 361-371.

44. Corbel, M.J.; Tolari, F.; Yadava, V.K. Appropriate Body-Mass Index for Asian Populations and Its Implications. Lancet 2004, 363, 157-163. [CrossRef]

45. Petrides, K.V. Technical Manual for the Trait Emotional Intelligence Questionnaires (TEIQue); London Psychometric Laboratory: London, UK, 2009.

46. Mikolajczak, M.; Luminet, O.; Leroy, C.; Roy, E. Psychometric Properties of the Trait Emotional Intelligence Questionnaire: Factor Structure, Reliability, Construct, and Incremental Validity in a French-Speaking Population. J. Personal. Assess. 2007, 88, 338-353. [CrossRef] [PubMed]

47. Lee, P.H.; Macfarlane, D.J.; Lam, T.H.; Stewart, S.M. Validity of the international physical activity questionnaire short form (IPAQ-SF): A systematic review. Int. J. Behav. Nutr. Phys. Act. 2011, 8, 115. [CrossRef]

48. Recruitment Against 3\% Disabled Quota-Civil Service Rules. Available online: https://www.civilservicerules.com/2019/02/11 / recruitment-against-3-disabled-quota/ (accessed on 18 January 2021).

49. Cohen, J. Statistical Power Analysis for the Behavioral Sciences; Academic Press: Cambridge, MA, USA, 2013; ISBN 1-4832-7648-1.

50. Field, A. Discovering Statistics Using IBM SPSS Statistics; Sage Publication: Thousand Oaks, CA, USA, 2013 ; ISBN 1446274586.

51. Peterson, R.A. A Meta-Analysis of Variance Accounted for and Factor Loadings in Exploratory Factor Analysis. Mark. Lett. 2000, 11, 261-275. [CrossRef]

52. Aslankhani, M.A.; Abdoli, B.; Zamani Sani, S.; Fathi Rezaei, Z. Emotional Intelligence in Athletes with Disabilities. Evol. Psychol. (Iran. Psychol.) 2009, 6, 15-24.

53. Bostani, M.; Saiiari, A. Comparison Emotional Intelligence and Mental Health between Athletic and Non-Athletic Students. Procedia Soc. Behav. Sci. 2011, 30, 2259-2263. [CrossRef]

54. Li, G.S.-F.; Lu, F.J.; Wang, A.H.-H. Exploring the Relationships of Physical Activity, Emotional Intelligence and Health in Taiwan College Students. J. Exerc. Sci. Fit. 2009, 7, 55-63. [CrossRef]

55. Movahedi, A.; Mojtahedi, H.; Farazyani, F. Differences in socialization between visually impaired student-athletes and nonathletes. Res. Dev. Disabil. 2011, 32, 58-62. [CrossRef]

56. Dursun, O.B.; Erhan, S.E.; Ibiş, E.Ö.; Esin, I.S.; Keles, S.; Sirinkan, A.; Yoruk, O.; Acar, E.; Beyhun, N.E. The effect of ice skating on psychological well-being and sleep quality of children with visual or hearing impairment. Disabil. Rehabil. 2014, 37, 783-789. [CrossRef]

57. Di Cagno, A.; Iuliano, E.; Aquino, G.; Fiorilli, G.; Battaglia, C.; Giombini, A.; Calcagno, G. Psychological well-being and social participation assessment in visually impaired subjects playing Torball: A controlled study. Res. Dev. Disabil. 2013, 34, 1204-1209. [CrossRef]

58. Mumcu, H.E.; Acet, M.; Kusan, O.; Zambak, Ö.; Koç, M.C. Examining to see elite sight-disabled athletes according to the dimensions of the scale of motivation in sport. J. Hum. Sci. 2017, 14, 2590-2600. [CrossRef]

59. Shipley, N.; Jackson, M.; Segrest, S. The Effects of Emotional Intelligence, Age, Work Experience, and Academic Performance. Res. High. Educ. J. 2010, 1-18. [CrossRef]

60. Dimick, J.A. The Effects of Emotional Intelligence on Age, Academics, Gender, and Sport Performance in Collegiate Athletes; Trevecca Nazarene University: Nashville, TN, USA, 2017; p. 144. 
61. Ozcorta, E.J.F.; Torres, B.J.A.; Buñuel, P.S.-L. Inteligencia emocional percibida y el bienestar psicológico de estudiantes universitarios en función del nivel de actividad física.(Perceived emotional intelligence and the psychological well-being of university students depending on the practice of physical activity). Cult. Cienc. Deporte 2015, 10, 31-39.

62. Suliga, E.; Cieśla, E.; Rębak, D.; Kozieł, D.; Głuszek, S. Relationship Between Sitting Time, Physical Activity, and Metabolic Syndrome Among Adults Depending on Body Mass Index (BMI). Med. Sci. Monit. 2018, 24, 7633-7645. [CrossRef] 